Pacific Northwest

National Laboratory

Operated by Battelle for the

U.S. Department of Energy

\title{
Report On Cost-Effectiveness And Energy Savings From Application Of Low-Cost Wireless Sensing
}

\author{
M. Kintner-Meyer \\ J. Skorpic \\ L. Reid
}

December 2004

\author{
Prepared for the \\ U.S. Department of Energy \\ Prepared for the U.S. Department of Energy \\ under Contract DE-AC06-76RL01830
}




\title{
DISCLAIMER
}

This report was prepared as an account of work sponsored by an agency of the United States Government. Neither the United States Government nor any agency thereof, nor Battelle Memorial Institute, nor any of their employees, makes any warranty, express or implied, or assumes any legal liability or responsibility for the accuracy, completeness, or usefulness of any information, apparatus, product, or process disclosed, or represents that its use would not infringe privately owned rights. Reference herein to any specific commercial product, process, or service by trade name, trademark, manufacturer, or otherwise does not necessarily constitute or imply its endorsement, recommendation, or favoring by the United States Government or any agency thereof, or Battelle Memorial Institute. The views and opinions of authors expressed herein do not necessarily state or reflect those of the United States Government or any agency thereof.

\author{
PACIFIC NORTHWEST NATIONAL LABORATORY \\ operated by \\ BATTELLE \\ for the \\ UNITED STATES DEPARTMENT OF ENERGY \\ under Contract DE-AC05-76RL01830
}

Printed in the United States of America
Available to DOE and DOE contractors from the Office of Scientific and Technical Information,
P.O. Box 62, Oak Ridge, TN 37831-0062;
ph: (865) 576-8401
fax: $(865)$ 576-5728
email: reports@adonis.osti.gov

\begin{abstract}
Available to the public from the National Technical Information Service, U.S. Department of Commerce, 5285 Port Royal Rd., Springfield, VA 22161 ph: (800) 553-6847 fax: $(703) 605-6900$ email: orders@ntis.fedworld.gov online ordering: http://www.ntis.gov/ordering.htm
\end{abstract}

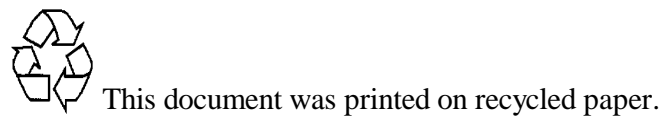




\section{Report On Cost-}

Effectiveness And Energy Savings From Application Of LowCost Wireless Sensing

M. Kintner-Meyer

J. Skorpic

L. Reid

December 2004

Prepared for the

U.S. D epartment of Energy

Pacific Northwest National Laboratory

Richland, Washington 99352 


\section{SUMmARY}

The rapid maturity of everyday wireless technologies - now widely used for mobile phones, wireless internet access, and even the replacement of barcodes - has had a tremendous impact on our ability to collect information from the physical world. There are tremendous opportunities in using wireless technologies for communicating with sensors and controls for building operation, but the market adoption rate of wireless systems in building automation is limited by two factors. First, the cost of the wireless sensing technology is still high because of the small production numbers. Second, the issues surrounding adoption of wireless technologies for building controls are not well understood. The key promise of wireless technology in building operation is to reduce the cost of installing data acquisition and control systems. Installation costs typically represent $20 \%$ to $80 \%$ of the cost of a sensor and control point in a heating, ventilation, and air-conditioning (HVAC) system - reducing or eliminating the cost of installation has a dramatic effect on the overall installed system cost. With low-cost wireless sensor and control systems, not only will the cost of system installation be significantly reduced, but it will become economical to use more sensors, thereby establishing highly energy efficient building operations and demand responsiveness that will enhance our electric grid reliability.

This report characterizes commercially available wireless technologies that are already being used in building applications or that are suitable for use in commercial buildings. The discussion provides an overview of fundamental concepts of radial broadcasting systems, as well as mesh networks, and will highlight the opportunities and challenges in their integration into existing wired control networks.

This report describes two demonstration projects of wireless sensors and their integration into existing control networks and discusses their cost per sensor, their ease of installation, and their reliability. It also describes the load control strategies implemented as a consequence of having the additional data provided by the wireless sensors and provides estimates of the resulting energy and cost savings. The report concludes with presentation of some general future prospects for wireless technologies in buildings applications. 
TABLE OF CONTENTS

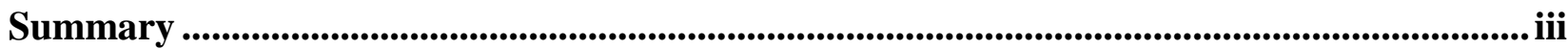

Acronyms ........................................................................................................................................ vii

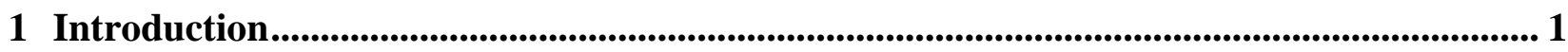

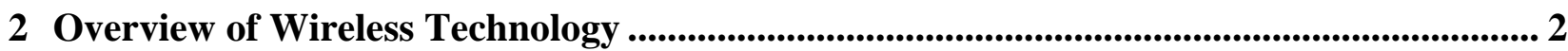

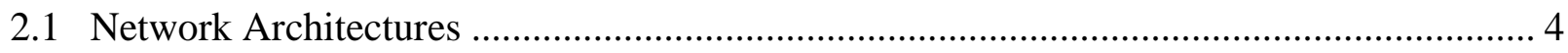

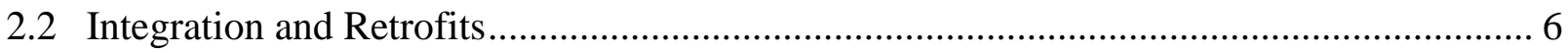

3 Demonstration of Wireless Sensors in Buildings ......................................................................... 7

3.1 Demonstration 1: Office Building ......................................................................... 7

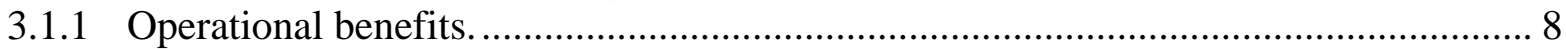

3.1.2 Energy-efficiency benefits .................................................................................. 8

3.2 Demonstration 2: Laboratory/Office Building ............................................................... 8

3.2.1 Description of the wireless temperature sensor network …………………............... 9

3.2.2 Installation and setup of wireless network ............................................................. 10

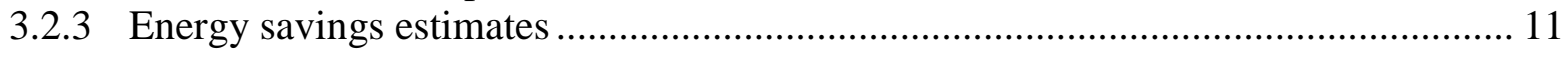

4 Discussion of Cost for Demonstration Projects............................................................................ 12

5 What is Next? Future Outlook On Wireless Technology for Building Applications ....... 14

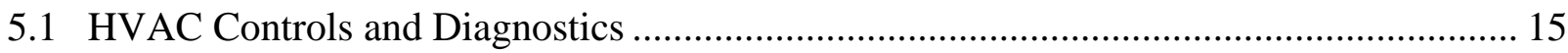

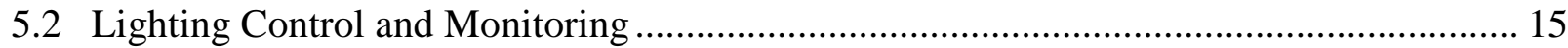

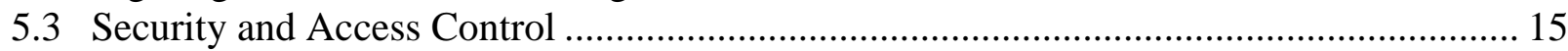

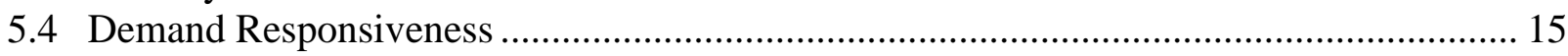

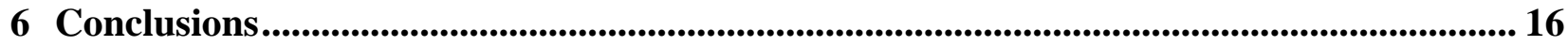

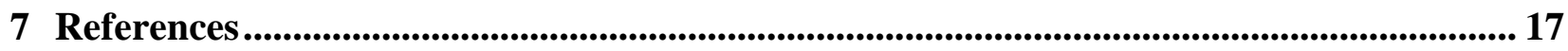




\section{FIGURES}

Figure 1: Wireless Device and Networking Standards .............................................................. 2

Figure 2: Three Popular Wireless Network Topologies ...............................................................5

Figure 3: Layout of Building 2. Forty Wireless Sensors are Placed in each Office Wing with a

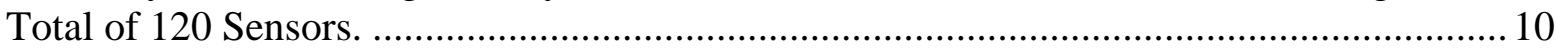

Figure 4: Installed Cost per Sensor for Buildings 1 and 2 ........................................................ 13 


\section{TABLES}

Table 1: Installation Costs of Wireless Sensors in Two PNNL Demonstration Buildings ............7 


\section{ACRONYMS}

$\mathrm{ACH}$

ASHRAE

COP

EMCS

HVAC

IC

IEEE

ISM

LAN

PAN

RF

VAV air changes per hour

American Society of Heating Refrigeration and Air-Conditioning Engineers, Inc.

coefficient of performance

energy management and control system

heating, ventilating and air conditioning

integrated circuit

Institute of Electrical and Electronic Engineers, Inc.

industrial, scientific, medical

local area network

personal area network

radio frequency

variable air volume 


\section{INTRODUCTION}

While a promising technology for the building automation industry, wireless communications in HVAC controls are still in their infancy at best and are not commonly used. A 1999 expert roundtable of HVAC industry professionals unanimously agreed that the wireless sensing of indoor conditions will be inevitable, promoting more localized and personalized control of indoor climates (Ivanovich and Gustavson 1999). Experts agree that the primary driver for deployment of wireless sensors will be cost advantages over wired systems and the flexibility to relocate thermostats and sensors as the interior building layout adapts to the changing organizational needs of the occupants. While the mobility of wireless sensors is irrefutable, the cost of wireless technology at the current time may still be too high for it to penetrate the market more widely. This may soon change. According to a 2004 market assessment of wireless sensor networks, the cost of radio frequency (RF) sensor modules is projected to drop below $\$ 12$ per unit in 2005 and drop further to $\$ 4$ per unit by 2010 (Chi and Hatler 2004). While these costs reflect only one portion of a wireless sensor, the sensor cost is also expected to decrease with technology advancements. For instance, digital integrated humidity and temperature sensors at high volumes are currently commercially available for less than $\$ 3$ per sensor probe $^{1}$. The general trend in sensor technology development toward solid state technology is likely to produce low-cost sensors for the mass markets.

Advancements in the sensor and wireless industries provide a significant opportunity for building owners, operators, and energy service companies to consider controls upgrades to improve overall energy efficiency, become more demand responsive, and to improve indoor environmental conditions. Controls improvements in commercial buildings are not expected to occur rapidly; however, the steady price reduction of wireless sensors and controls products is likely to accelerate adoption of the technology in the commercial building market sector.

To date, however, end-users are caught between enthusiasm for the benefits that wireless sensing and control can provide and skepticism that the technology will operate reliably compared to wired systems. While advancements of wireless local area networks (LANs) have paved the road for wireless technology in the market, they also have made end-users aware of the inherent reliability challenges of wireless transmission inside buildings and facilities. Furthermore, with the increasing awareness of cyber-space vulnerabilities of modern facility and building automation, additional protection requirements are being imposed on wireless network technology, which runs counter to the general attempt to simplify technology to reduce cost. Many of these challenges are currently being addressed by technology vendors and standards committees to provide technology solutions with the necessary technical performance that the market demands.

\footnotetext{
${ }^{1}$ Quote by SenSolution, Newberry Park, CA. February 2004.
} 


\section{OVERVIEW OF WiRELESS TECHNOLOGy}

There are a large number of wireless network technologies on the market today, and "wireless networks" as a technology span from cellular phone networks to wireless temperature sensors. This confusing array of wireless technologies choices is, on the whole, not fully developed nor targeted to building automation applications, where ease of installation and low costs are top priorities. The functionality of many of the existing and emerging wireless standards is not well matched to building automation applications.

In building automation applications, where line connection to power will likely not be conveniently available to every sensor, power consumption is of critical importance. "Peel-and-stick" temperature sensors that use batteries will only be realized with very low power wireless devices and networks; 3 - to 5-year battery lifetime is a minimum. Although power is generally available in commercial buildings, it is often not available at the precise location where sensors are placed. Thus, for many wireless sensors, powering by batteries will be necessary to keep the installed cost low. Figure 1 shows the power consumption and data rate for several wireless communications standards. The IEEE 802.11a, b, and g Standards (also referred to as "WiFi" for wireless fidelity), which were developed for mobile computing on wireless LANs, are at the high end of both data rate and power consumption. While these standards have proven very popular for mobile web browsing, they are not suitable for most building automation applications because of the high power consumption, limitations on the number of devices in a network, and the cost and complexity of the radio chipsets.

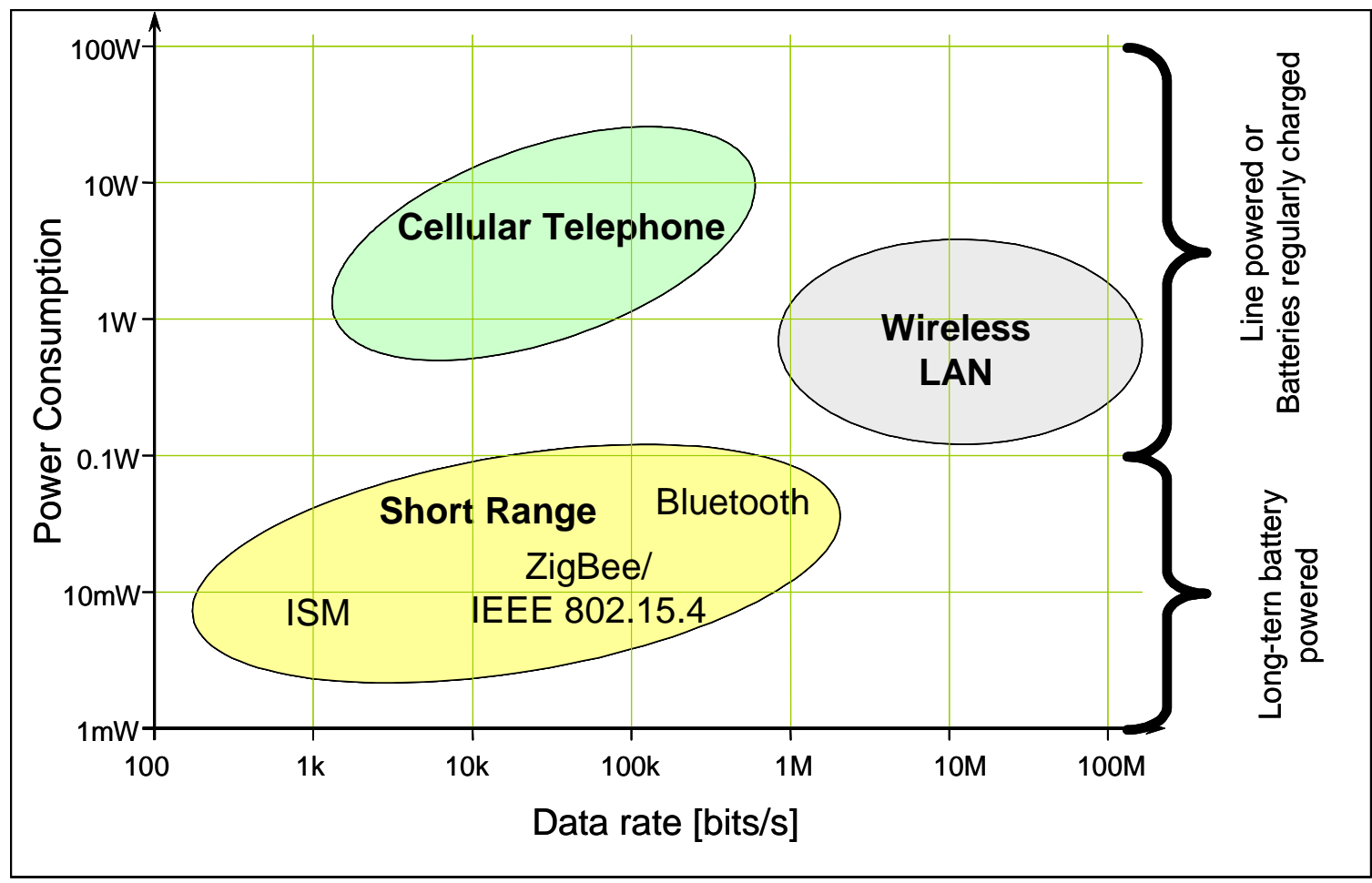

Figure 1: Wireless Device and Networking Standards 
Bluetooth, another wireless communications standard, was developed for personal area networks (PANs) and has proven popular for wireless headsets an cordless phones (Bluetooth 2001). The data rate and power consumption of Bluetooth radios are both less than for WiFi, which puts them closer to the needs of the building automation applications, but the battery life of a Bluetooth-enabled temperature sensor is still only in the range of weeks to months - not the 3- to 5-years minimum requirement for building applications. The number of devices in a Bluetooth network is also severely limited, making the technology applicable for only the smallest in-building deployments.

The IEEE 802.15.4 Standard, which was approved in 2003, is designed specifically for low data rate, low power consumption applications including building automation and also devices ranging from toys, wireless keyboards and computer mice to industrial monitoring and control (IEEE 2003). For battery-powered devices, this technology is built to specifically address applications where a trickle of data is coming from sensors and sent out to actuators. The communication distance of the 802.15.4 radio devices is in the range of 100 to 300 feet for typical buildings, which, when coupled with an effective network architecture, provides excellent functionality for typical building automation applications.

The industry group ZigBee Alliance developed a specification (called ZigBee) that is built upon the physical radio specification of the IEEE 802.15.4 Standard (Kinney 2003). ZigBee adds logical network, security, and application software. It was created to address the market need for a cost-effective, standards-based wireless networking solution that supports low data rates, low power consumption, security, and reliability. ZigBee defines both star and mesh network topologies, a variety of data security features, and interoperable application profiles.

There are also non-standardized radios operating with proprietary communication protocols. They offer further improved power consumption with optimized features for building automation applications. These radios often are classified as ISM (industrial, scientific, medical) radios referring to the industrial, scientific, and medical bands of the frequency spectrum (the bands also used by IEEE 802.15.4/Zigbee, Bluetooth, and WiFi). The existence of these radio devices, however, is not sufficient for implementation of low-power reliable wireless networks. The network architecture - defining how wireless devices communicate with each other, how networks are installed and managed, and how the overall network reliability is ensured - is critical to the overall fulfillment of the promise of modern wireless networks for building automation. 


\subsection{Network Architectures}

There are many issues to consider when choosing a wireless networking technology for a particular application, and effective decisions must be driven by the requirements of the application. As mentioned above, for most building automation applications, the most important network criteria are reliability, ease and cost of installation, and power consumption. The wireless network design with the best combination of these critical operating parameters is the network topology of choice.

Figure 2 shows three typical network topologies: a star network, where each device talks to a central hub or receiver, a repeater network, where "leaf" nodes communicate to repeaters that talk to a central hub, and a mesh network, where each device in the network can communicate to any of its neighbors within the communication distance.

The star network is the simplest of the possible network topologies. Before standard integrated-circuit (IC) manufacturing technologies were capable of making high performance radios inexpensively, the only cost-effective wireless network was the star network because the sensor nodes often had only transmitters; they did not have two-way communication capabilities. Because both radio functionality and microprocessor capabilities were severely limited, the most basic network topology was the only economically viable choice. Star networks may be limited in overall network size by the communication distance of any one node. Each link in the network infrastructure is a single point of failure, leaving no redundancy in the network. Installation is simple because no configuration is necessary. Because there is only one path from the sensor node to the receiver or hub, placement often requires an RF site survey to determine where to place each sensor and the receiver to achieve network connectivity. Overall, the star network proved useful, relatively simple, and low cost. It may be limited in desired ease of installation, expandability, and robustness if the original communication path is interrupted. 
Star network

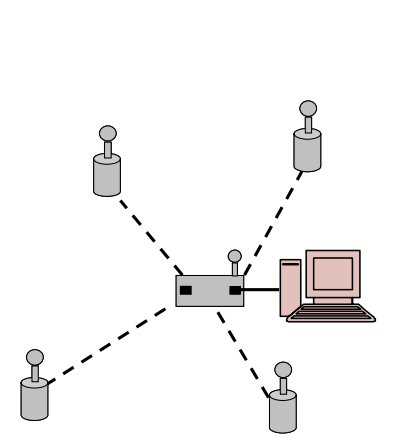

Star/Router network

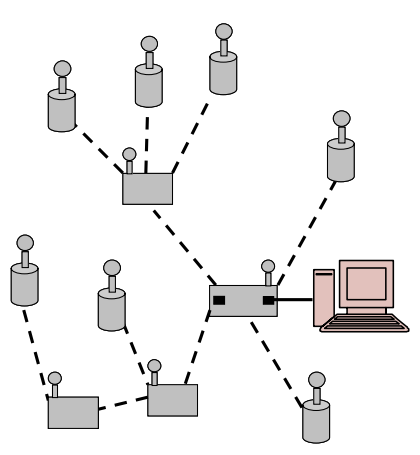

Mesh network

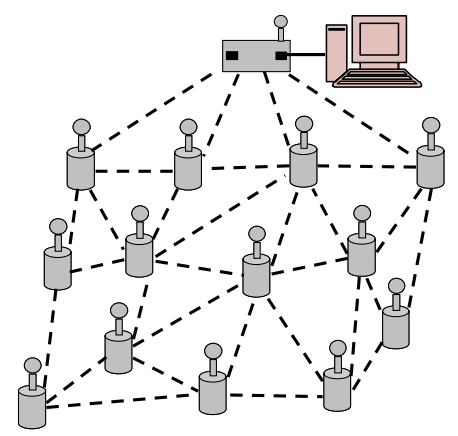

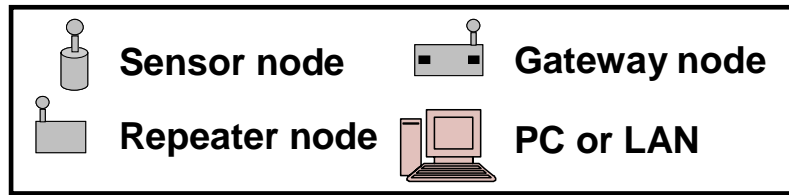

Figure 2: Three Popular Wireless Network Topologies

With the wide availability of IC transceivers, many wireless networks now use repeaters in conjunction with a star network to extend the range of the network. The star/repeater networks, like those used in the demonstration systems described in this paper, allow for much larger effective ranges than simple star networks and can often be used with large numbers of devices. However, use of these networks requires installation of wireless infrastructure - repeaters. This overhead may increase the per-sensor cost of the wireless network as the wireless networks grow.

With the dramatically reduced cost of microprocessors and memory, additional computation at the device level can now be used to operate a more complex network, which simplifies both the installation and commissioning process while maximizing reliability. These mesh networks - where each device in the network acts both as a repeater and a sensor node - allow the largest communication range of the star/repeater network, and also provide increased total network reliability. The devices in a mesh network automatically determine which nearby neighbors can communicate effectively, and route data through the network accordingly. Having multiple links in a network provides built-in redundancy so data can be effectively routed around blocked links - this means that there are no single points of failure in the system, so the overall networks can be extremely reliable even if individual wireless links are not. Mesh networks also pass data from one node to another in the network, making the placement of additional sensors or controls in the network akin to extending the wireless network. As additional devices are placed in a mesh network, the number of additional paths is increased, thereby improving the network reliability.

The main disadvantage of the mesh network is the use of wireless data channels for network management and maintenance, which not only uses part of the available radio 
bandwidth, but also drains batteries. For high-bandwidth applications, the network traffic on a critical node can be prohibitively high, and thus, can drain the battery too quickly. For low-data-rate applications, however, this limitation may be manageable.

Additionally, the sophisticated network routing scheme requires an overhead on hardware and firmware, adding a premium to the overall cost. The new mesh technology is in the nascent stages of market development, with products just entering the building automation market.

There are a wide variety of wireless networks available today, ranging in price from hundreds of dollars per sensor down to about $\$ 80$ per sensor for the technology used in the demonstration system described below. With the continuous reduction in the size, cost, and power consumption of IC technology, the cost of the radio chipsets will likely continue to decrease to the point where the battery will be the largest component of the overall hardware cost. This decrease in cost, however, is also quite closely tied to shipment volumes. As an example, TechKnowledge predicts that WiFi chipset prices will decline from \$16 in 2003 to less than \$6 at the end of 2004 - a tremendous price drop that is correlated with a near doubling of chipset volume (TechKnowledge 2003).

As these devices are rolled out into high-volume building automation applications, the high-volume manufacture of wireless networking devices with the appropriate sensors and packaging will result in very low cost wireless sensors. The additional silicon cost for the computation and memory required for mesh-network devices will be a miniscule fraction of the total device cost, so it is likely that the additional reliability from the mesh network topology may drive their widespread use.

\subsection{Integration and Retrofits}

For effective widespread adoption of wireless technologies, it will be necessary to integrate these new systems with existing wired building systems. As the number of wireless devices grows, the need for network management tools and wireless diagnostics emerges. Effective wireless networks for building automation applications will need to provide mechanisms for integration with existing open and proprietary standard systems. As with wired systems, the integration of disparate systems into an integrated whole will be a challenge that must be faced by vendors and systems integrators in the industry. 


\section{Demonstration of Wireless Sensors in Buildings}

Pacific Northwest National Laboratory (PNNL) performed demonstrations by instrumenting two buildings on its campus with wireless sensors for measuring indoor-air temperatures. The objective of the demonstrations was to investigate the communication robustness of wireless sensor networks, the ease with which a wireless sensor network can be integrated into the existing wired energy management and control system (EMCS), and to quantify the cost effectiveness compared to conventional wired sensors.

\subsection{Demonstration 1: Office Building}

Thirty battery-powered wireless temperature sensors, three line-powered repeaters, one receiver, and one integration module for interfacing with a Johnson Controls N2 Network $^{2}$ were installed in the spring of 2002. The wireless sensor network used a proprietary communications protocol. The temperature sensors measure zone-air temperatures at dispersed locations throughout a $70,000-\mathrm{ft}^{2}$ office building. The building is a concrete-steel structure extending over three floors. The sensors are installed with double-sided tape against concrete walls or office dividers. Every 10 minutes, the temperature sensors communicate the temperature measurements to a receiver either directly or via one of the three repeaters. The wireless network is interfaced to the N2 network bus at a control panel on the first floor. The cost for the wireless technology, including installation, was estimated to be about $\$ 4020$. See Table 1 for more details on the cost.

Table 1: Installed Costs of Wireless Sensors in Two PNNL Demonstration Buildings

\begin{tabular}{|l|r|r|r|r|r|}
\cline { 2 - 6 } \multicolumn{1}{c|}{} & \multicolumn{2}{c|}{ Building 1 } & \multicolumn{2}{c|}{ Building 2 } \\
\cline { 2 - 6 } \multicolumn{1}{c|}{} & $\begin{array}{c}\text { Cost per } \\
\text { unit }\end{array}$ & Quantity & $\begin{array}{c}\text { Total } \\
\text { Cost }\end{array}$ & Quantity & $\begin{array}{r}\text { Total } \\
\text { Cost }\end{array}$ \\
\hline Temperature sensors & $\$ 50$ & 30 & $\$ 1,500$ & 120 & $\$ 6,000$ \\
\hline Repeaters & $\$ 250$ & 3 & $\$ 750$ & 0 & $\$ 0$ \\
\hline Receiver & $\$ 200$ & 1 & $\$ 200$ & 3 & $\$ 600$ \\
\hline Translator & $\$ 450$ & 1 & $\$ 450$ & 3 & $\$ 1,350$ \\
\hline RF surveying labor & $\$ 80 /$ hour & 2 hours & $\$ 160$ & 2 hours & $\$ 160$ \\
\hline Integrator configuration labor & $\$ 80 /$ hour & 4 hours & $\$ 320$ & 8 hours & $\$ 640$ \\
\hline Installation of integrator labor & $\$ 80 /$ hour & 8 hours & $\$ 640$ & 8 hours & $\$ 640$ \\
\hline Total Cost & & & $\$ \mathbf{4 4 , 0 2 0}$ & & $\$ 9,390$ \\
\hline Cost per Sensor & & & $\mathbf{\$ 1 3 4}$ & & $\$ 78$ \\
\hline
\end{tabular}

Further details on the wireless technology, the placement of sensors, and the HVAC system in the demonstration building can be found in Kintner-Meyer and Brambley (2002). This section focuses on the use and the cost savings that were achieved as a result of the additional zone-air temperature measurements.

\footnotetext{
${ }^{2} \mathrm{~N} 2$ bus is a Johnson Controls network protocol used for the Johnson Metasys building automation system.
} 


\subsubsection{Operational benefits.}

Several improvements were observed from an operational and energy-efficiency perspective. Operationally, the wireless sensors enabled the facility staff to respond to 'hot' and 'cold' complaints much more effectively than before their installation.

Utilizing the mobility of a wireless sensor, a spare sensor can be easily taped directly into a small localized problem area for temporary monitoring of air temperature over a few hours or days. Because the 30 zone-air temperature sensors provided a much higher spatial resolution of temperature measurements, the facility staff recognized problems with individual variable-air-volume (VAV) boxes that were causing uneven supply air distribution, which in turn caused a significant range of air temperatures throughout the building. After repairing the faulty VAV boxes, the facility staff was able to raise the supply-air temperature by $2^{\circ} \mathrm{F}$, thus, alleviating the need for overcooling some zones to deliver enough cooling capacity through the faulty VAV boxes serving other zones. The VAV-box repair improved thermal comfort and eliminated the occasional use of space heaters during the early morning hours both during the summer and winter months.

\subsubsection{Energy-efficiency benefits}

The energy-efficiency benefits are directly related to the repair of several VAV box controllers, the reset of the supply-air temperature by $2^{\circ} \mathrm{F}$ during cooling periods, and the avoidance of small space-heater use. In addition, a chilled-water reset strategy was implemented based on an averaged value of the 30 zone-air temperatures. This allowed the chilled-water temperature to fluctuate between 45 and $55^{\circ} \mathrm{F}$, the temperature depending on the average measured zone-air temperature. Prior to installing the wireless temperature sensors, the chilled-water temperature was fixed at $45^{\circ} \mathrm{F}$. The average zoneair temperature was used as an indicator for meeting the cooling loads. The associated cost savings from the higher coefficient of performance (COP) (about 7\% improvement on average) at higher chilled-water temperatures were estimated at about $\$ 3500$ over the cooling season (May through September), even accounting for the slightly increased fan power consumption for any given cooling load. Additional energy savings were achieved by the avoiding the use of individual space heaters and resetting the supply-air set point to provide an estimated total annual savings of about $\$ 6000$. Based on this estimate, the simple payback time for the wireless technology was about 7 months.

\subsection{Demonstration 2: Laboratory/Office Building}

The second building has laboratories and offices. It opened for occupancy in 1997 . The gross floor space is about 200,000 $\mathrm{ft}^{2}$ with three protruding office wings of about 49,000 $\mathrm{ft}^{2}$ each. Only the office area was used for the demonstration. Each office wing has a separate air-handling unit and a VAV ventilation system. Each VAV box supplies air to two offices controlled by a thermostat located in one of the two offices. The construction of the office area consists of metal studs with gypsum wallboard. Offices contain metal book shelves, and at a minimum, two computers with large screen monitors. The office space is relatively metal-rich, posing a challenge for the wireless communication between the sensors to the receivers. 
Before installation of the wireless sensor system, facility staff had explored night setback options for the ventilation of the office space that would turn off the air-handling units during the night hours after 6 p.m., but decided not to implement such a strategy out of concern that those offices without a thermostat might be occupied during late hours and if so, that the air temperatures in those offices might exceed the thermal comfort limits. Because of this concern, the ventilation system operated continuously on a 7-day/week 24-hour/day schedule. Facility staff believed that if each office were equipped with a temperature sensor, night setback could be used and suspended if the zone temperature in either office served by a VAV box exceeded a upper threshold of $78^{\circ} \mathrm{F}$. A cursory cost estimate from a controls vendor for installing wired temperature sensors in those offices without a thermostat yielded an installed cost per sensor of about $\$ 500$, which exceeded the acceptable cost for the retrofit option.

After the initial positive experiences with wireless sensors for buildings applications in 2002 , facility staff re-examined the viability of ventilation night setback using wireless temperature sensors and decided to implement the wireless temperature system in early 2004. The same wireless temperature sensor network technology, as deployed in Building 1, was used. Familiarity with the technology and experience gained from the first wireless demonstration greatly reduced the level of effort for a RF survey of the building and the wireless network setup.

\subsubsection{Description of the wireless temperature sensor network}

Forty wireless temperature sensors were deployed in each of the three office wings of Building 2, bringing the total to approximately 120 sensors (see Figure 3). Each office not previously equipped with a thermostat received a wireless temperature sensor. The temperature signals were received by three receivers, each located at the base of the office wing and connected via the integrator to the Johnson Controls network control module. The wireless network consisted of a total of 120 sensors and 3 receivers and integrators. Facility staff tested the need for repeaters and found that with the use of one receiver for each wing, the communication was sufficiently robust. An alternative wireless network design could have been to install one receiver in the middle wing and potentially use repeaters to assure the communication from the most distant transmitters in the exterior wings. Each integrator, however, can serve no more 100 transmitters, so 120 sensors could not be installed using this configuration; therefore, this alternative was rejected. 


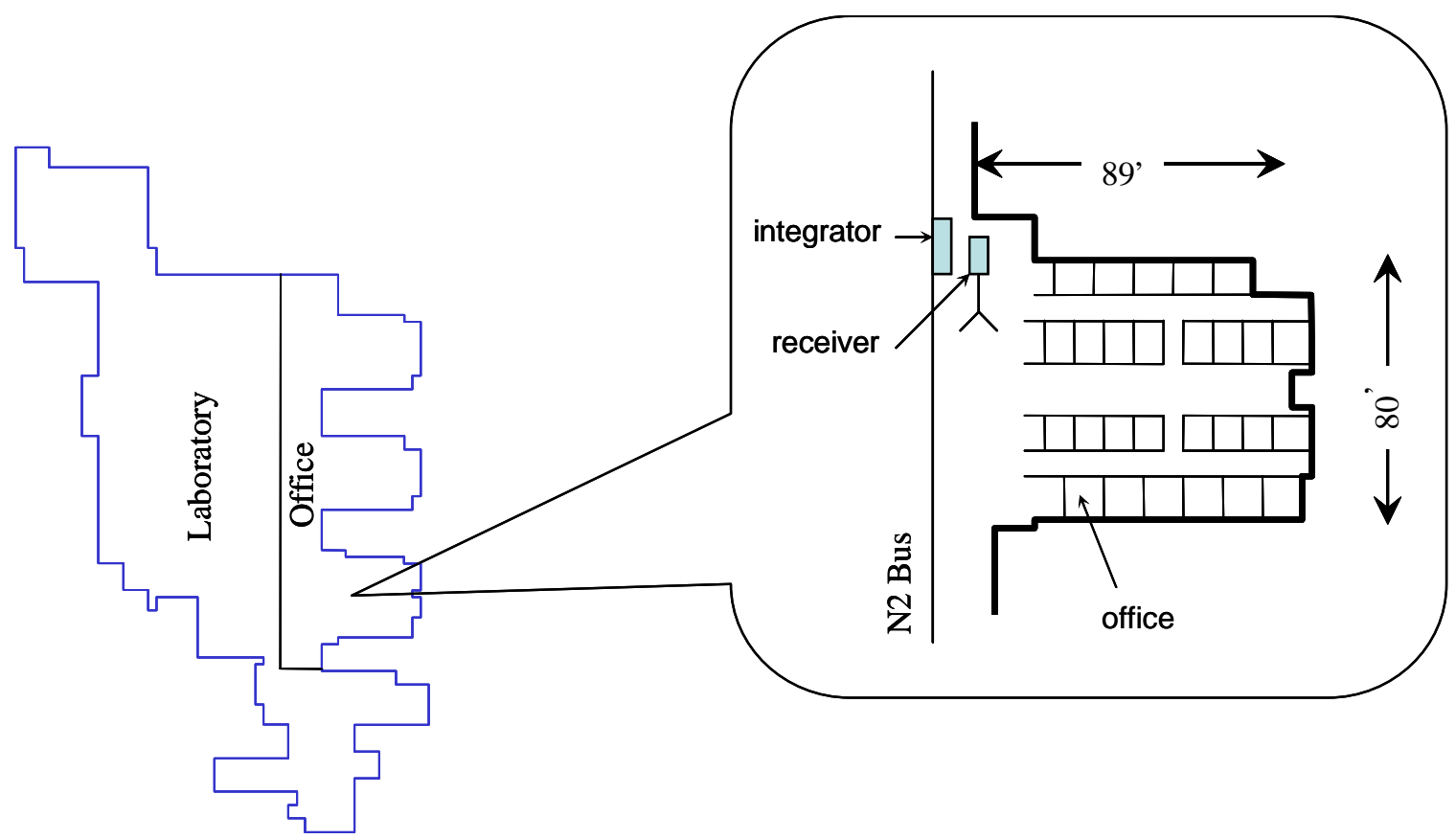

Figure 3: Layout of Building 2. Forty Wireless Sensors are Placed in each Office Wing for a Total of 120 Sensors.

The temperature sensors are programmed to transmit a temperature measurement every 10 minutes. Earlier transmission occurs when a pre-set temperature change limit is sensed; this is to enable facility staff to notice rapid temperature changes in spaces over shorter times than the usual transmission interval. The wireless sensor is battery powered with a 3 -Volt " $2 / 3 \mathrm{~A}$ " size lithium battery, which is expected to last between 5 and 8 years at the 10-minute transmission rate.

\subsubsection{Installation and setup of wireless network}

The installation costs for the wireless sensor network were minimal. They included a 2hour RF survey, an original setup of the integrator device to specify the number and ID numbers of the sensors, and the physical connection of the integrator to the Johnson Controls network control module. The integrator configuration for set up of 120 sensors was conservatively estimated to be 8 hours, accounting for the fact that the configuration was done in stages (one wing at a time). The integrator installation involves physically connecting the $24-\mathrm{VAC}$ power supply provided in the Johnson Control network module and connecting to the Johnson Controls N2 bus using a three-wire shielded cable. A short four-wire cable connects the integrator and the receiver, providing power and communication between the two devices. This work was performed by an instrument technician. The sensors were then attached to the office walls using double-sided tape.

The supervisory control program was augmented to schedule the night setback starting at 6 p.m. and suspending it if an office-zone temperature exceeded a threshold temperature of $78^{\circ} \mathrm{F}$ during the cooling season and $55^{\circ} \mathrm{F}$ during the heating season. 
Table 1 presents the cost components for the two demonstration buildings. The capital costs for the hardware represent the costs to PNNL, and are representative of what a large volume purchaser might pay. List prices would commonly be significantly higher than those shown.

\subsubsection{Energy savings estimates}

Initial estimates showed that the energy savings are largely caused by shutdown of the supply and return fans and, to a lesser degree, to reduced thermal loss during the night as the temperature is allowed to float. Trend logs of runtime using the new night setback strategy were used to estimate the electric energy savings. The preliminary savings estimate suggested that the night setback could achieve savings of approximately $\$ 5000$ annually. Verification of the savings estimates is planned after completing 1 full year of night setback operations. We attribute the cost savings to the wireless sensors because they enabled implementation of the ventilation night setback; without them, facility staff would not have implemented night setback. 


\section{Discussion of Cost for Demonstration Projects}

Cost for the sensor and controls technology is a critical factor for the viability of any retrofit project or even in new construction. As was already reported (Kintner-Meyer and Brambley 2002 and Kintner-Meyer et al. 2002), the wireless sensor solution was slightly cost-effective compared to an equivalent wired solution for Building 1. For Building 2, the per-sensor cost was significantly less than the estimated cost for the wired sensor retrofit. These examples indicate that wireless sensor networks in the two PNNL demonstration buildings can compete on the basis of cost. While this finding is important for comparing wired against wireless solutions, it may not be sufficient to induce facility managers to recognize that wireless sensors can enable new advanced controls and diagnostics opportunities currently not viable with wired technology. In this section, we discuss the cost of wireless sensor networks in terms of incremental cost for adding new wireless sensors. In both demonstration buildings, the wireless network infrastructure is sufficient to accommodate significantly more sensors at the cost of sensors alone. In other words, with the entire Building 1 and the office section of Building 2, we have sufficient reception anywhere in the zones for additional transmitter signals to reach the receiver without adding more wireless infrastructure. This enables us to add sensors at a cost of the sensor itself plus a minimal setup time (a few minutes) for configuring the integrator.

Figure 4 shows the cost curves for both demonstration buildings as a function of the number of sensors installed. The cost curves for the two buildings are not only similar in shape but also in absolute terms. The cost difference between the two buildings is relatively small. At 30 sensors, the difference is $\$ 22 /$ sensor $(\$ 160-\$ 138)$ and at 120 sensors \$6/sensor (\$78-\$22). This suggests that the cost on a per-sensor basis is relatively similar for these two very different buildings structures. Although further cost data from additional wireless installations are needed to confirm this hypothesis, it appears that the cost relation with respect to numbers may be in a relatively small range for a given wireless technology across a range of commercial buildings structures. If this can be confirmed through additional cost data, it could be very useful as a cost estimating tool for energy-efficiency retrofit measures. 


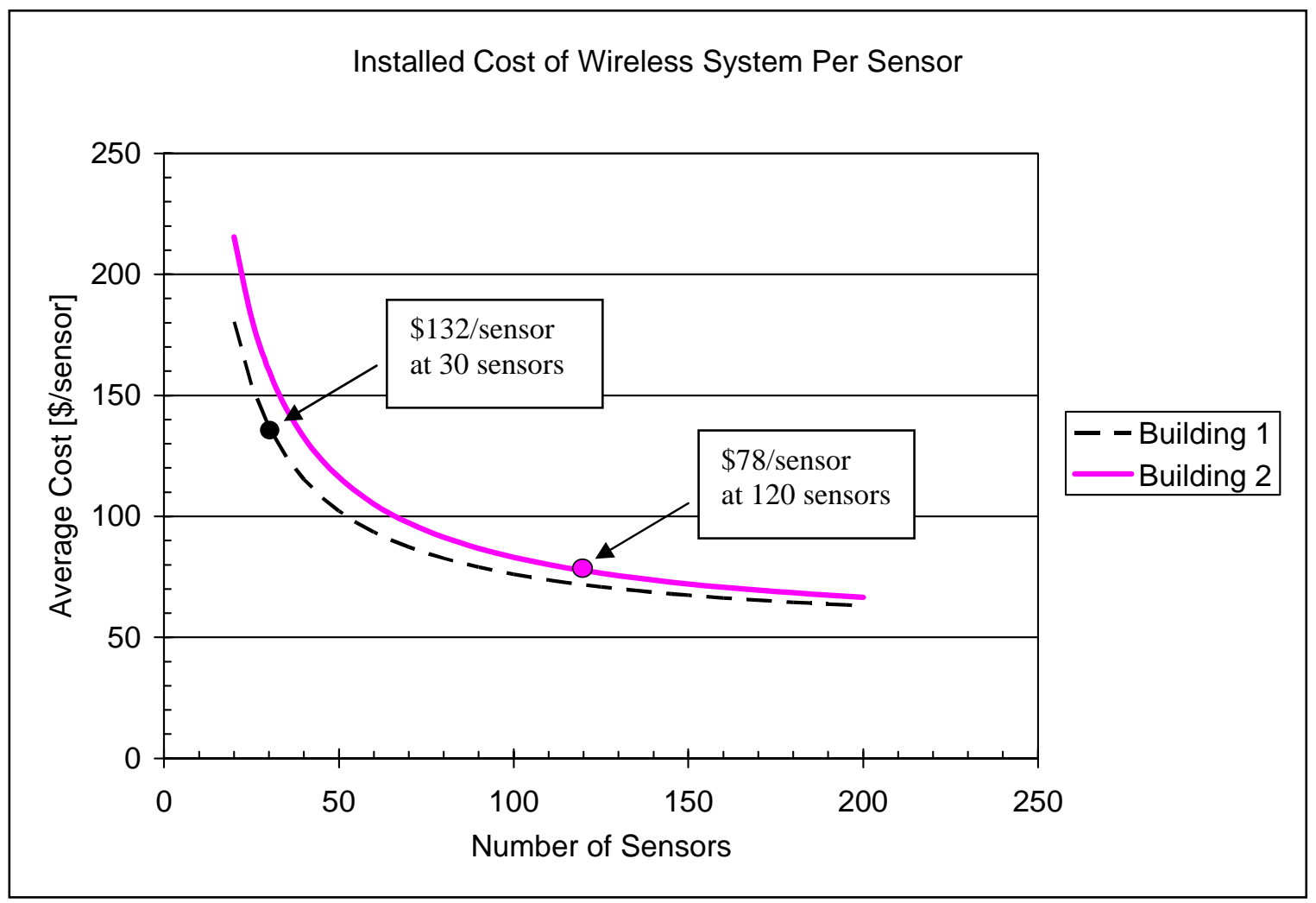

Figure 4: Installed Cost per Sensor for Buildings 1 and 2

The second insight from Figure 4 relates to the decline in average system cost per sensor, decreasing as the number of sensors becomes large. For large quantities, the cost curve asymptotically approaches the cost of one sensor ( $\$ 50 /$ sensor). This finding points out that further cost reductions of wireless networks must come from reducing the cost of the sensor modules rather than dropping the cost of infrastructure components, such as the receivers, transmitters, and repeaters. This insight is reflected by the industry's current technology development efforts and the industry's approach of communicating target prices of sensor/transmitter devices rather than some of the necessary infrastructural technologies. However, in the interim as the industry is developing and wireless sensors penetrate the markets, it is important to recognize that the quantity of sensors at any given site is likely to be small. During this maturation phase of the wireless technology, it is important to recognize that the wireless infrastructure will contribute a significant part of the total system costs (and average system cost per sensor). 


\section{What is Next? Future Outlook On Wireless Technology for Building APPLICATIONS}

The steadily growing number of technology companies offering products and services for monitoring and control applications fuels the expectation that the sub- $\$ 10$ wireless sensor is likely to be available in the near future. When we reach that point of technological advancement, the cost of the battery may then be the single largest cost item of a wireless module. Even the battery may be replaceable by ambient power scavenging devices that obviate the need for a battery as a power source. A self-powered sensor device creates fundamentally new measurement applications, unthinkable with battery-powered technology. For instance, sensors can be fully embedded in building materials, such as structural members or wall components. They can measure properties in the host material that currently cannot be accessed by external measurement probes. In the energy efficiency domain, new diagnostic methods could be envisioned that will use embedded sensors for early diagnostics to prevent equipment failure and degradation of energy efficiency.

Researchers are exploring different ambient sources for the extraction of electric power. Mechanical vibration emanating from rotary energy conversion equipment, such as internal combustion engines, pumps, and fans, can be converted into electric power by induction driving a magnetic element inside a coil. Alternatively, piezo-electric materials generate an electric potential when mechanically strained. Current research and technology development focuses on maximizing the energy extraction of mechanical energy by adaptive techniques that sense and adjust to a given vibration frequency and amplitude to maximize the power extraction. Thermo-electrical power generators utilize the Seebeck Effect, commonly used in thermocouple probes for temperature measurements. A few degrees Celsius of a temperature differential can, in cleverly designed probes, generate power in the micro-Watt range. The small power generation from all ambient power devices can then be stored in a capacitor to operate the wireless sensor when needed.

Recent new releases about prototypes of ambient energy scavenging devices that generate sufficient electric power to operate a wireless sensor give rise to anticipate and hope that these revolutionary technologies will soon be commercially available (FerroSolutions 2003).

With an optimistic outlook on cost projections of wireless sensors and revolutionary selfpowering devices, what are the likely impacts and opportunities of this technology for the building sector in general, and for energy-efficiency improvement opportunities in buildings in particular? While the scenario of ubiquitous sensing by miniaturizing sensors the size of the particles in metal-flake paint that can be painted on a wall may be in the realm of science fiction, there are real near-term opportunities for low-cost wireless devices providing value in the building sector. The following bullets identify potential earlier applications: 


\subsection{HVAC Controls and Diagnostics}

- Higher spatial resolution of zonal temperature and humidity to assure high thermal comfort: Causes of localized heat build-up can be detected and diagnosed. Each office or cubical would be equipped with one or more temperature/humidity sensors.

- Expand VAV box control from a commonly used single thermostat control point to multiple sensors located in each office or cubical: Average temperature that is more representative of the thermal needs could be used to control that VAV box.

- Retrofit VAV box diagnostics: Because there are hundreds, sometimes thousands, of VAV boxes in a commercial building, wireless sensors measuring volumetric airflow and temperature would allow cost-effective retrofit to diagnose problems.

- Additional outdoor-air temperature sensors for improved economizer control. Ideally, place one or more air-temperature sensors in air intakes to air-handlers to minimize bias of radiative heat transfer.

- Equip packaged rooftop HVAC systems with sensors to monitor performance: For economizer control diagnostics, perform air-side measurements of supply air, mixed air, and return air. For diagnostics of charging level and heat exchanger performance, measure temperatures and pressures in the vapor compression cycle.

\subsection{Lighting Control and Monitoring}

- In open-space office buildings, retrofit lighting controls for individual and localized control from the occupants' desks.

- Retrofit reconfigurable lighting systems with individually addressable dimmable ballasts.

- Retrofit light sensors at the work space to turn off lighting fixtures in zones that are well lit by daylight.

- Retrofit wireless sensors and control points at lighting panels to turn off lights during unoccupied periods.

\subsection{Security and Access Control}

- Motion sensors and door sensors for physical security systems.

- Environmental monitoring and physical security for IT systems and server rooms.

- Access control systems for retrofits and new construction.

\subsection{Demand Responsiveness}

- Retrofit wireless power meters on major loads to modulate or switch off power during grid emergencies or during periods of high power prices. This includes pumps, fans, lighting, and other larger energy consuming equipment.

- Retrofit appliances with wireless devices to receive price signals or load control instructions to respond to electric power grid stress. 


\section{Conclusions}

Building automation is the art and science of using sensors and controls to optimize building performance. Getting information to and from control systems to the distributed sensing and actuating points throughout a building has long been the most cumbersome and expensive part of building automation systems. The use of wireless technology promises to simplify the deployment and extend the functionality of these systems by making the use of more sensors economical, as well as making the systems easy to reconfigure. The economical use of wireless in the two demonstrations at the PNNL shows that wireless technology is deployable today and that wireless systems often have advantages beyond simply replacing wires.

The relentless push forward in semiconductor manufacturing processes will continue to drive down the cost of wireless networking devices while improving their functionality, creating an opportunity for more complex networking protocols that will improve system reliability, decrease system installation and provisioning costs, and create an overall system flexibility unachievable with wired systems. To date, the adoption rate of wireless technology in building automation applications has been slow because of the unfamiliarity of the technology and the typical cautious and risk-averse mentality in this industry. However, with more successful technology demonstrations and falling cost of wireless networking technologies, wireless systems are poised to make significant inroads, particularly in retrofit applications. Perhaps if building automation systems follow in the footsteps of the telephone, wireless building automation may become the rule rather than the exception. 


\section{References}

Bluetooth SIG Inc. 2001. Specification of the Bluetooth System. Version 1.2, November 5, 2003. Available online at https://www.bluetooth.org/spec/.

Chi, C., and M. Hatler. 2004. "Wireless Sensor Network: Mass Market Opportunities." Q1 2004. By ON World. Available online at: http://www.onworld.com. February 2004.

FerroSolutions. 2003. Energy Harvesters and Sensors. FerroSolutions. Roslindale, MA. Available at http://www.ferrosi.com/files/FS_product_sheet_wint04.pdf.

IEEE 802.15.4. 2003. Low-Rate Wireless Personal Area Networks. Enabling Wireless Sensors with IEEE 802.15.4. IEEE Press, New York, NY.

Ivanovich, M., and D. Gustavson. 1999. "The Future of Intelligent Buildings is Now." Heating/Piping/Air Conditioning Engineering, Vol. 71, No. 9, May 1999, pp. 7379.

Kinney, P. 2003. ZigBee Technology: Wireless Control that Simply Works. ZigBee Alliance. Available at http://www.zigbee.org/en/resources/.

Kintner-Meyer, M., M. Brambley, T. Carlon, and N. Bauman. 2002. "Wireless Sensors: Technology and Cost Savings for Commercial Buildings." In Proceedings of the 2002 ACEEE Summer Study on Energy Efficiency in Buildings, pp. pp. 7.121 7.134. American Council for an Energy-Efficient Economy. Washington, D.C.

Kintner-Meyer, M., and M. R. Brambley. 2002. "Pros and Cons of Wireless in Buildings". ASHRAE Journal, Vol. 44, No. 11 (November 2002), pp 54-61. American Society of Heating, Refrigeration, and Air-conditioning Engineers, Inc. Atlanta, GA.

TechKnowledge Group. 2003. "Chip Sets for Wireless Networking," TechKnowledge Group. Scottsdale, AZ. 